\begin{tabular}{|c|c|c|c|c|}
\hline$k_{F} a_{v}$ & $=$ liquid-film mass transfer coefficient & {$[l / \mathrm{min}]$} & $\theta$ & $=$ time, $t-\varepsilon_{b} Z / u$ \\
\hline$k_{s} a_{v}$ & $=$ solid-phase mass transfer coefficient & {$[l / \mathrm{min}]$} & $\rho_{p}$ & $=$ apparent density of particle \\
\hline $\mathrm{Pe}$ & $=$ Peclet number of axial dispersion based & & $\rho_{t}$ & $=$ true density of particle \\
\hline & particle diameter & {$[-]$} & $\tau_{\ell}$ & $=$ tortuosity factor, $\varepsilon_{p t} D_{m} / D_{e}$ \\
\hline$q$ & $=$ amount adsorbed on particle & {$[\mathrm{cc} / \mathrm{g}]$} & \multicolumn{2}{|r|}{ Literature Cited } \\
\hline $\operatorname{Re}$ & $=$ Reynolds number based on particle diar & $\operatorname{meter}_{[-]}$ & 1) & Kawazoe, K. and T. Kawai: Kagaku Kōgaku, 32, 11 \\
\hline$S c$ & $=$ Schmidt number & {$[-]$} & & (1968). \\
\hline$t$ & $=$ time & [min] & 2) & Longsworth, L. G.: J. Phys. Chem., 67, 689 (1963). \\
\hline$u$ & $=$ superficial velocity & {$[\mathrm{cm} / \mathrm{min}]$} & 3) & Miyauchi, T. and Kikuchi: Chem. Eng. Sci., 30, 343 (1975). \\
\hline$V_{F}$ & $\begin{array}{l}=\text { velocity of adsorption front defined by } \\
\text { Eq. (4) }\end{array}$ & {$[\mathrm{cm} / \mathrm{min}]$} & 4) & $\begin{array}{l}\text { Satterfield, C. N.: "Mass Transfer in Heterogeneous Cataly- } \\
\text { sis", M.I.T. Press (1970). }\end{array}$ \\
\hline$Z$ & $=$ bed length & {$[\mathrm{cm}]$} & 5) & $\begin{array}{l}\text { Shirotsuka, T., T. Togami and I. Yokoyama: Kagaku } \\
\text { Kogaku, 34, 44 (1970). }\end{array}$ \\
\hline$\beta$ & $=$ adsorption coefficient & {$[\mathrm{cc} / \mathrm{g}]$} & 6) & Takeuchi, K. and Y. Uraguchi: J. Chem. Eng. Japan, 10, \\
\hline$\gamma$ & $=$ packed density & {$[\mathrm{g} / \mathrm{cc}]$} & & $297(1977)$ \\
\hline$\varepsilon_{b}$ & $=$ bed voidage & {$[-]$} & 7) & Wilson, E. J. and C. J. Geankoplis: Ind. Eng. Chem., \\
\hline$\varepsilon_{p t}$ & $=$ total porosity of particle & {$[-]$} & & Fundam., 5, 9 (1966). \\
\hline
\end{tabular}

\title{
BOUNDARY OF HYDRODYNAMIC FLOW REGION AND GAS- PHASE MASS-TRANSFER COEFFICIENT IN PACKED COLUMN WITH COCURRENT DOWNWARD FLOW
}

\author{
Susumu FUKUSHIMA AND KATSUHIKo KUSAKA \\ Department of Chemical Engineering, Kansai University, Suita 564
}

\section{Introduction}

Cocurrent flow operation is to be preferred in cases where the mean driving force is not affected by flow direction, as in the absorption of an acid gas by a highly alkaline solution. In particular, this case is an operation under a high gas and a low liquid flow rate. The estimation of gas-phase volumetric coefficients of mass transfer, $k_{g} a_{p}$, for spray, pulse and wavy flow regions is thus important in designing and operating the columns.

For cocurrent downward operations, Reiss ${ }^{5}$ and Gianetto et $a l^{4}{ }^{4}$ have presented empirical equations for $k_{g} a_{p}$ in terms of dissipated energy and other factors. Shende and Sharma ${ }^{8}$ have also reported empirical equations in terms of gas and liquid flow rates. There are few reports of empirical equations for gas-phase mass-transfer coefficient $k_{g}$. Gianetto et $a l^{4}{ }^{4}$ have only reported the equation in terms of dissipated energy and other factors for the pulse flow region.

It was presented in the earlier papers ${ }^{11}$ that the

Received December 2, 1977 . Correspondence concerning this article should be addressed to $\mathrm{S}$. Fukushima. dependence of interfacial area $a_{p}$ on the gas Reynolds number $R e_{g}$ and the liquid Reynolds number $R e_{l}$ is distinctly different in spray, pulse, wavy, dispersed bubble and trickle flow regions, and that the empirical equations of hydrodynamic flow boundaries are obtained by combining two of the equations for $a_{p}$. These equations of flow boundaries were also obtained from the equations of liquid-phase volumetric coefficients of mass transfer, $k_{l}^{*} a_{p}$, in a similar fashion to that described in the early papers ${ }^{2}$.

We had three objectives in this investigation. The first was to obtain the empirical equations of hydrodynamic flow boundaries by analysing the literature data on $k_{g} a_{p}$ in the fashion mentioned above. The second was to obtain an empirical equation of $k_{g}$. The third was to compare the predicted values with the experimental data on the absorption rate of sulfur dioxide from factory exhaust gas into water.

\section{Gas-Phase Volumetric Coefficients of Mass Transfer and Hydrodynamic Flow Boundary}

Figure 1 shows the dependence of $k_{g} a_{p}$ on $R e_{l}$ and $R e_{g}$ obtained from rearrangement of the literature 


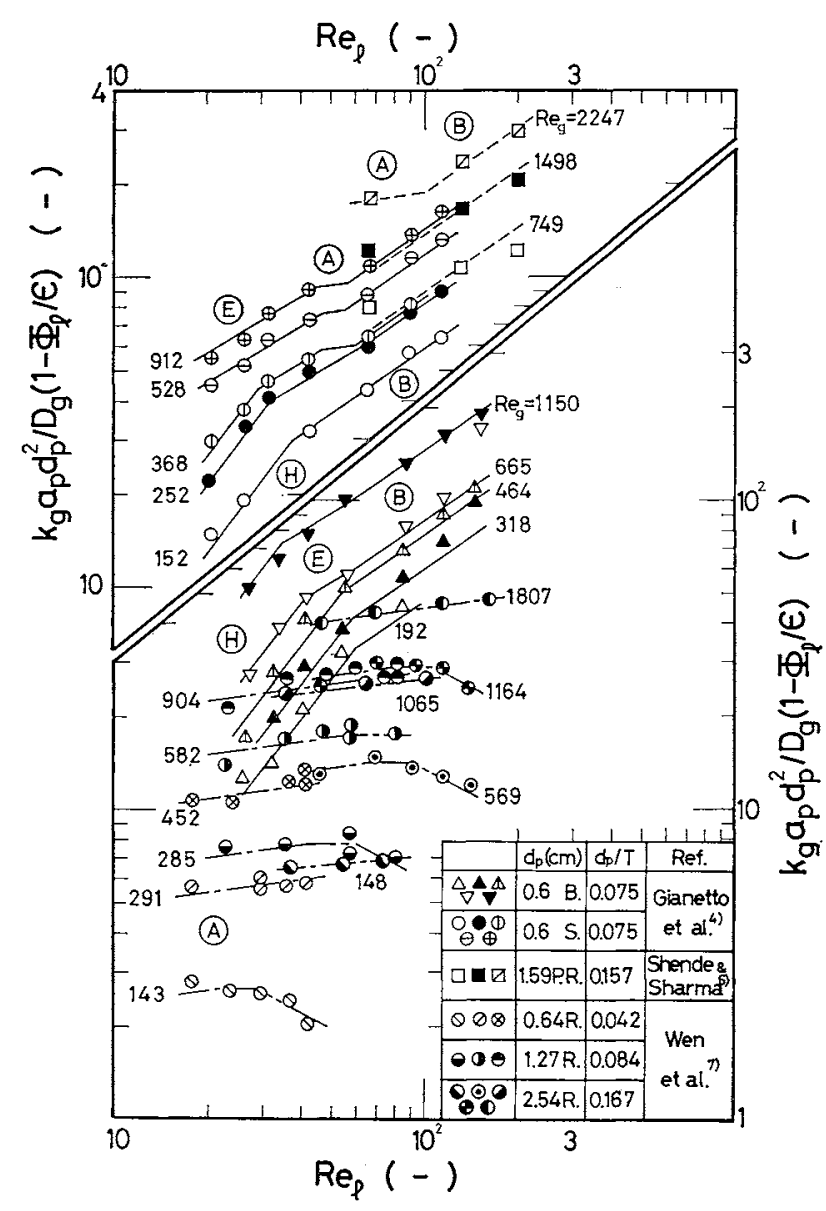

B. : Berl saddles, P.R.: Pall rings, R.: Raschig rings, $\mathbf{S}$.: spheres

Fig. 1 Rearrangement of the literature data on gas-phase volumetric coefficients of mass transfer

data, where the liquid holdup $\Phi_{l}$ is estimated by the equations in the earlier papers ${ }^{11}$. For ammonia gas absorption into $2 \mathrm{~N}-\mathrm{Na}_{2} \mathrm{SO}_{4}$ solution for $0.6 \mathrm{~cm}$ spheres and Berl saddles, the Gianetto data ${ }^{4}$ are significantly divided into $\mathbf{A}, \mathbf{B}, \mathbf{E}$ and $\mathbf{H}$ regions. For sulfur dioxide gas absorption into $2 \mathrm{~N}-\mathrm{NaOH}$ solution for $5 / 8$ in. Pall rings, the Shende data ${ }^{6)}$ pertain to $\mathbf{A}$ and $\mathbf{B}$ regions. The Wen data ${ }^{7}$, on dehumidification of air by $\mathrm{CaCl}_{2}$ solution for various sizes of Raschig rings, also pertain to $\mathbf{A}$ region.

The empirical equations of $k_{g} a_{p}$ for $\mathbf{A}, \mathbf{B}$ and $\mathbf{E}$ regions were thus obtained, on the assumption that the value of $k_{g}$ is proportional to the square root of diffusivity in gas-phase $D_{g}$, as follows:

For flow region $\mathbf{A}$

$$
\frac{k_{g} a_{p} d_{p}^{2}}{D_{g}\left(1-\Phi_{l} / \varepsilon\right)}=1.9 \times 10^{-1} \phi^{-0.7} R e_{l}^{0.15} R e_{g}^{0.9} S c_{g}^{1 / 2}\left(d_{p} / T\right)^{-0.2}
$$

For flow region $\mathbf{B}$

$$
\frac{k_{g} a_{p} d_{p}^{2}}{D_{g}\left(1-\Phi_{l} / \varepsilon\right)}=1.7 \times 10^{-1} \phi^{-0.7} \operatorname{Re}_{l}^{0.7} \operatorname{Re}_{g}^{0.6} S c_{g}^{1 / 2}\left(d_{p} / T\right)^{-0.2}
$$

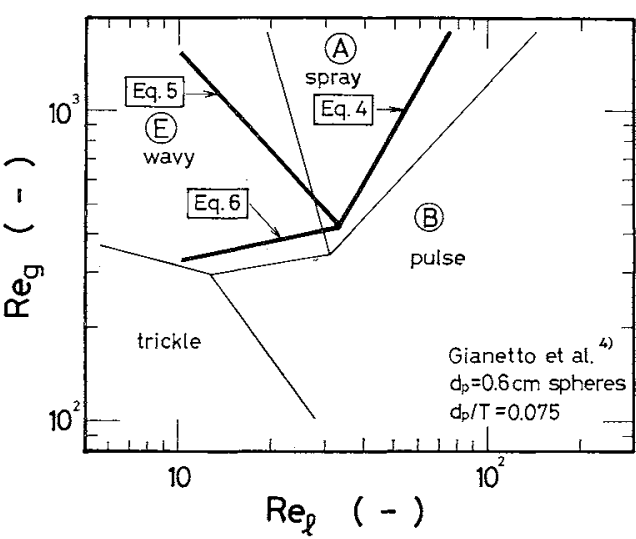

Fig. 2 Boundaries of hydrodynamic flow regions for $0.6 \mathrm{~cm}$ spheres

For flow region $\mathbf{E}$

$$
\frac{k_{g} a_{p} d_{p}^{2}}{D_{g}\left(1-\Phi_{l} / \varepsilon\right)}=1.9 \times 10^{-2} \phi^{-1.7} R e_{l}^{0.6} R e_{g}^{1.3} S c_{g}^{1 / 2}
$$

The equations of hydrodynamic flow boundaries may be thus given by combining two of these equations for $k_{g} a_{p}$ as follows:

For boundary A-B

$$
1.1=R e_{l}^{0.55} R e_{g}{ }^{-0.3}
$$

For boundary $\mathbf{A}-\mathbf{E}$

$$
10=\phi^{-1.0} R e_{l}^{0.45} R e_{g}^{0.4}\left(d_{p} / T\right)^{0.2}
$$

For boundary $\mathbf{B}-\mathbf{E}$

$$
8.9=\phi^{-1.0} \operatorname{Re}_{l}^{-0.1} \operatorname{Re}_{g}^{0.7}\left(d_{p} / T\right)^{0.2}
$$

Figure 2 indicates that the predicted boundaries (thick lines) according to Eqs. (4), (5) and (6) are fairly close to those (thin lines) of spray-pulse, spray-wavy and pulse-wavy boundaries given by combining two of the equation on $a_{p}$ in the earlier papers ${ }^{1)}$, respectively, for $0.6 \mathrm{~cm}$ spheres, where $d_{p} / T=0.075$. It is thus found that the spray, pulse and wavy flow regions correspond to $\mathbf{A}, \mathbf{B}$ and $\mathbf{E}$ regions, respectively. Furthermore, the close resemblance between thick and thin lines suggests that the $k_{g}$ is roughly presented by the same equation for spray, pulse and wavy flow regions.

Even though the $\mathbf{H}$ region is placed at low $R e_{l}$ and $R e_{g}$, the dependence of $k_{g} a_{p}$ on $R e_{l}$ for $\mathbf{H}$ region is much larger than that for other regions. To obtain reasonable boundaries of pulse-trickle and wavytrickle flows, the $k_{p} a_{p}$ at low $R e_{l}$ and $R e_{g}$ must be further investigated.

\section{Gas-Phase Mass-Transfer Coefficient}

The equation of $k_{g}$ was obtained by dividing $k_{g} a_{p}$ by $a_{p}$, where the value of $a_{p}$ for respective flow regions is given by the equation in the earlier papers ${ }^{11}$. Hence, the equation for pulse flow region is obtained from Eq. (2) as follows:

$$
S h_{g}=\frac{k_{g} d_{p}}{D_{g}}=8.0 \times 10^{2} \phi^{-0.4} \operatorname{Re}_{g}^{0.4} S \mathcal{C}_{g}^{1 / 2}\left(d_{p} / T\right)^{2.3}
$$


Table 1 Comparison of predictions with the data on absorption of $\mathrm{SO}_{2}$ into water in pulse flow region

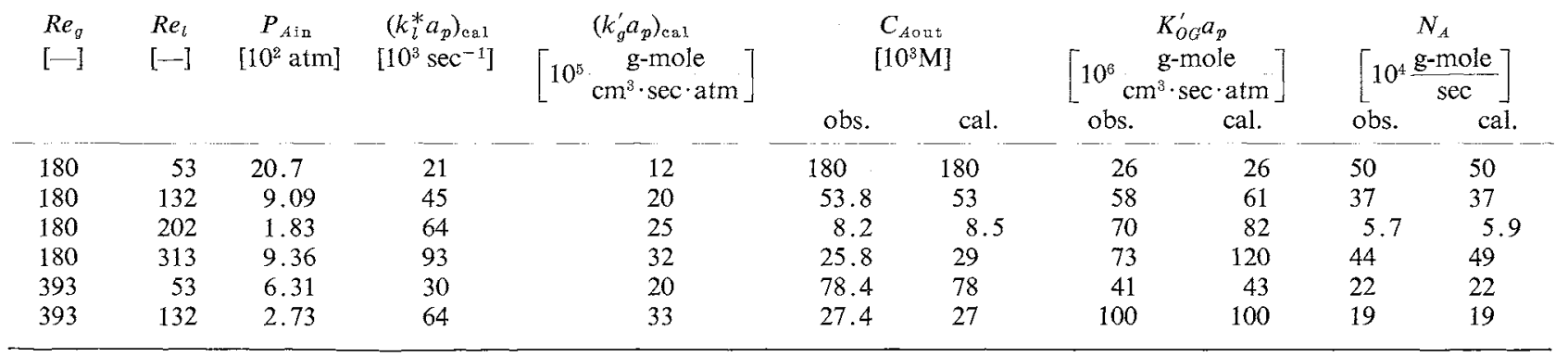

Although the equations for spray and wavy flow regions were also obtained from Eqs. (1) and (3), the predicted values of $k_{g}$ from those equations do not show much difference in comparison with the values given by Eq. (7).

There are available data on $k_{g}$ given by Gianetto et al. ${ }^{4}$ for $0.6 \mathrm{~cm}$ Berl saddles and by Shende and Sharma ${ }^{6}$ for 1 in. Pall rings and 1 in. Intalox saddles. Other data on $k_{g}$ for spray, pulse and wavy flow regions were also obtained by dividing the literature data on $k_{g} a_{p}$ by $a_{p}$ estimated from the equation in the earlier papers ${ }^{11}$. The correlation of Eq. (7) and these data agree within $\pm 30 \%$ error, except for the Wen data $^{7}$ ) at high $R e_{l}$, as shown in Fig. 3. The observed value of $k_{g} a_{p}$ given by Wen et al. ${ }^{7)}$ decreases as $R e_{l}$ increases at high $R e_{l}$ in Fig. 1, but this abnormal result has not been found in other investigations.

\section{Physical Absorption of Sulfur Dioxide with Water}

\section{1 Experimental}

The absorption of $\mathrm{SO}_{2}$ from exhaust gas of a chemical factory into water was performed at $26.4 \pm 0.5^{\circ} \mathrm{C}$ in a packed column, $10 \mathrm{~cm}$ in diameter and $100 \mathrm{~cm}$ in height, using $1 / 2$ in. ceramic spheres, as described in the earlier papers ${ }^{1)}$. The partial pressure of $\mathrm{SO}_{2}$ at the column inlet, $P_{A_{\text {in }}}$, was varied from 0.0183 to 0.207 $\mathrm{atm}$, where the total pressure is $1 \mathrm{~atm}$. On the assumption that the bulk of liquid is in piston flow, the overall volumetric coefficient of mass transfer, $K_{O G}^{\prime} a_{p}$, was determined by the difference of $\mathrm{SO}_{2}$ content in liquid phase at the inlet and the outlet.

The diffusivities of $\mathrm{SO}_{2}$ for gas and liquid phase at $30^{\circ} \mathrm{C}$ are respectively $0.14 \mathrm{~cm}^{2} / \mathrm{sec}$ given by Shende and Sharma $\left.{ }^{6}\right)$ and $2.5 \times 10^{-5} \mathrm{~cm}^{2} / \mathrm{sec}$ given by Whitney and Vivian $^{8)}$. The effects of temperature on these diffusivities for gas and liquid phase are given by the Fuller $^{3)}$ and by the Stokes-Einstein equations, respectively.

\section{2 Comparison of predictions with the data}

Table 1 compares predictions with experimental data on absorption rate $N_{A}$. These operating conditions are placed in the pulse flow region from the map of hydrodynamic flow boundaries. The predicted values of $K_{O G}^{\prime} a_{p}$ are thus obtained by combination of

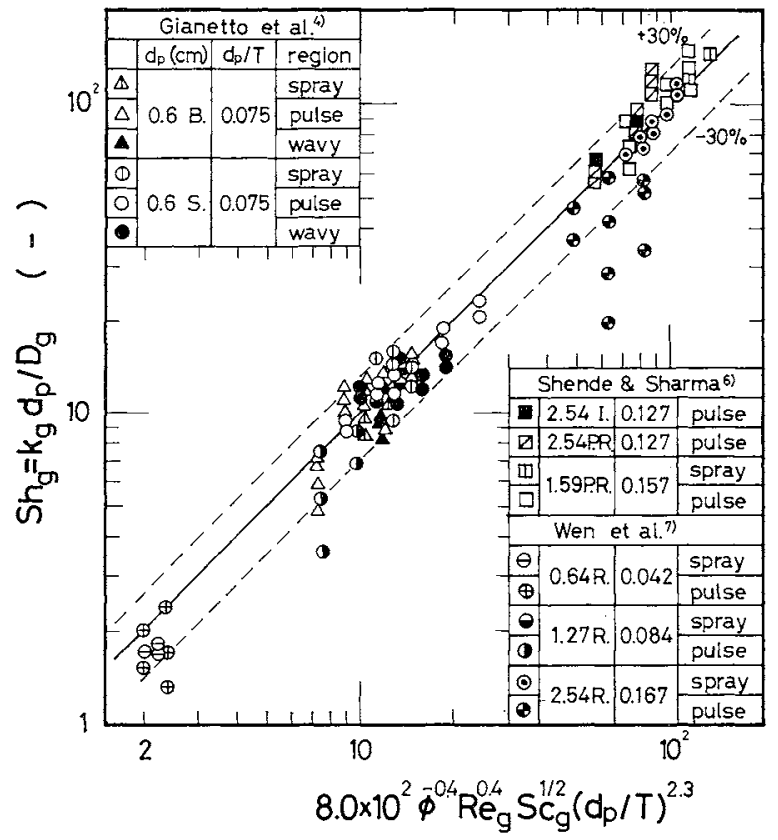

B.: Berl saddles, I.: Intalox saddles, P.R.:

Pall rings, R.: Raschig rings, S.: spheres

Fig. 3 Correlation of Eq. (7) and the data for spray, pulse and wavy flow regions

$k_{g}$ given by Eq. (7), $k_{l}^{*}$ and $a_{p}$ given by respective equations in the earlier papers ${ }^{1,2}$. The predicted $N_{A}$ are in good agreement with the data.

This result indicates that the empirical equations of $k_{g}, k_{l}^{*}$ and $a_{p}$ are useful in predicting absorption rate.

\section{Conclusions}

1. The empirical equations for spray-pulse, spraywavy and pulse-wavy flow boundaries were obtained from analysis of gas-phase volumetric coefficient of mass transfer. The predicted boundaries agreed fairly well with these boundaries as given from analysis of interfacial area in the earlier work.

2. The gas-phase mass-transfer coefficients are presented by the same equation for spray, pulse and wavy flow regions.

3. The predicted absorption rates of sulfur dioxide from exhaust gas in water are in good agreement with the experimental data. 


\section{Acknowledgment}

The authors express special appreciation to Messrs. M. Kumagai and T. Nakajima for their experimental assistance, and to Mr. M. Noda, president and Mr. M. Murakami, chief of research, Daito Chemical Company for offering an opportunity for gas absorption experiments.

\section{Nomenclature}

$a_{p} \quad=$ interfacial area per unit volume of packed column $\left[\mathrm{cm}^{-1}\right]$

$C_{\text {Aout }}=$ concentration of sulfur dioxide in water at outlet of column $\quad[\mathrm{g}$-mole $/ l]$

$D_{g} \quad=$ diffusivity in gas $\quad\left[\mathrm{cm}^{2} / \mathrm{sec}\right]$

$d_{p} \quad=$ packing diameter $\quad[\mathrm{cm}]$

$d_{s} \quad=$ equivalent diameter of packing based on sphere

$\begin{array}{ll}G \quad=\text { superficial mass velocity } & {\left[\mathrm{g} / \mathrm{cm}^{2} \cdot \mathrm{sec}\right]}\end{array}$

$K_{O G}^{\prime} \quad=$ overall mass-transfer coefficient based on gas phase $\quad\left[\mathrm{g}-\mathrm{mole} / \mathrm{cm}^{2} \cdot \mathrm{sec} \cdot \mathrm{atm}\right]$

$k_{q} \quad=$ gas-phase mass-transfer coefficient $\quad[\mathrm{cm} / \mathrm{sec}]$

$k_{g}^{\prime} \quad=$ gas-phase mass-transfer coefficient [g-mole $\left./ \mathrm{cm}^{2} \cdot \mathrm{sec} \cdot \mathrm{atm}\right]$

$k_{t}^{*} \quad=$ liquid-phase mass-transfer coefficient $\quad[\mathrm{cm} / \mathrm{sec}]$

$N_{A} \quad=$ absorption rate of sulfur dioxide [g-mole $\left./ \mathrm{sec}\right]$

$P_{A \text { in }} \quad=$ partial pressure of sulfur dioxide at inlet of column [atm]

Re $\quad=$ Reynolds number, $d_{s} G / \mu$

$S \quad=$ geometrical surface of packing $\quad\left[\mathrm{cm}^{2}\right]$

$S c_{g} \quad=$ Schmidt number in gas phase, $\mu_{g} / o_{g} D_{g} \quad[-]$

$S h_{g} \quad=$ Sherwood number in gas phase, $k_{g} d_{p} / D_{g} \quad[-]$

$$
=\text { column diameter }
$$

$=$ void fraction in packed column

$=$ viscosity

$=$ density

$=$ holdup of fluid per unit volume of packed column

$=$ surface shape factor of packing, $S / d_{p}^{2}$

〈Subscripts〉

$$
\begin{aligned}
& \text { cal. }=\text { calculated } \\
& g \quad \text { - gas-phase } \\
& l=\text { liquid-phase }
\end{aligned}
$$

\section{Literature Cited}

1) Fukushima, S. and K. Kusaka: J. Chem. Eng. Japan, 10, 461 (1977).

2) Fukushima, S. and K. Kusaka: ibid., 10, 468 (1977).

3) Fuller, E. N., P. D. Schettler and J. C. Giddings: Ind. Eng. Chem., 58, No. 5, 19 (1966).

4) Gianetto, A., V. Specchia and G. Baldi: $A I C h E J ., 19,916$ (1973).

5) Reiss, L. P.: Ind. Eng. Chem., Process Des. Dev., 6, 486 (1967).

6) Shende, B. W. and M. M. Sharma: Chem. Eng. Sci., 29, 1763 (1974)

7) Wen, C. Y., W. S. O'Brien and L. T. Fan: J. Chem. Eng. Data, 8, 42 (1963).

8) Whitney, R. P. and J. E. Vivian: Chem. Eng. Progr., 45, 323 (1949).

\title{
AN EFFECTIVE SUB-OPTIMAL FORMULATION OF THE SINGULAR AND/OR BANG-BANG CONTROL PROBLEM
}

\author{
TAKeICHIRo TAKAMATSU AND Yoshiaki SHIMIZU \\ Department of Chemical Engineering, Kyoto University, Kyoto 606
}

In a recent study Jacobson et $a l .^{3)}$ have proposed a computational method to solve the singular and/or bang-bang control problem in a sub-optimal manner.

This method has been applied to the optimal control problem of chemical processes by Edgar and Lapidus ${ }^{1 /}$ and it has been shown to be effective especially in the large dimensional cases with multiple controls.

Along with this approach, Nishida et $a l^{5}$. have proposed the piece-wise $M a x-H$ strategy to deal with the optimal control problem of dynamical systems.

In these studies more emphasis has been paid on generality and easiness of the algorithm than on strict-

Received October 31, 1977. Correspondence concerning this article should be addressed to Y. Shimizu, Research Reactor Institute, Kyoto Univ., Kumatori-cho Sennan-gun, Osaka 590-04. ness of the optimality. From the technical viewpoint sub-optimal formulation is preferable because of uncertainties in the system model or incomplete realization of the optimal policy.

This paper will present another approximation method which has computational advantages over previous methods.

\section{Statement of the Problem}

We are concerned with the following optimal problem:

$$
\operatorname{Min}_{\boldsymbol{u} \in U} J=K\left(\boldsymbol{x}\left(t_{f}\right)\right)+\int_{t_{0}}^{t_{f}} L(\boldsymbol{x}, t) d t
$$

subject to 